\title{
The role of passion for studies on academic procrastination and mental health during the COVID-19 pandemic
}

\author{
Evandro Morais Peixoto ${ }^{1} \cdot$ Ana Celi Pallini $^{1} \cdot$ Robert J. Vallerand ${ }^{2}$. \\ Sonia Rahimi ${ }^{2}$. Marcus Vinicius Silva ${ }^{1}$
}

Received: 21 January 2021 / Accepted: 17 April 2021 / Published online: 8 June 2021

(c) The Author(s), under exclusive licence to Springer Nature B.V. 2021

\begin{abstract}
Procrastination is a maladaptive behaviour that students often experience in academic activities and can result in negative consequences to mental health. The challenges imposed by the COVID-19 pandemic can contribute to increase procrastination behaviors in academic activities that the student does not like and in those he/she is passionate. The main objective of this research was to test an integrative model of passion, procrastination, satisfaction with life and psychological distress in students during pandemic. The sample was comprised of 416 university students aged between 18 and 57 years $\left(M_{\text {age }}=24.81 \pm 7.02,78.1 \%\right.$ women $)$. Structural Equation Modeling results revealed that academic procrastination is negatively linked to harmonious passion, and positively linked to obsessive passion. Academic procrastination in turn is negatively linked to satisfaction with life and positively linked to psychological distress. Harmonious passion also was directly positively associated to satisfaction with life and negatively associated to psychological distress. These results suggest that students' harmonious passion for their studies plays a protective role against academic procrastination and mental health indicators, while obsessive passion represents a risk factor.
\end{abstract}

Keywords Harmonious passion · Obsessive passion · Procastination · well-being · Positive psychology

Evandro Morais Peixoto peixotoem@gmail.com

1 Universidade São Francisco Campinas, São Paulo, Brazil

2 Université du Québec à Montréal, Montreal, Québec, Canada 


\section{Introduction}

Procrastination is a prominent maladaptive behaviour that occurs in many areas of life, such as when one postpones academic tasks or medical appointments. Research shows that $15 \%$ to $20 \%$ of the general population chronically procrastinates (Harriott and Ferrari, 1996; Steel, 2007). These numbers are even more pronounced in the academic context, where $80 \%$ to $95 \%$ of university students report having procrastinated at least one time (Ellis and Knauss, 1977; Harriott and Ferrari, 1996), and $46 \%$ of students report procrastinating frequently on academic activities (Solomon and Rothblum, 1984). However, research has shown that academic procrastination has negative consequences with respect to students' academic performance and life satisfaction (Balkis, 2013; Goroshit and Hen, 2019).

Researchers have also observed that procrastination in the academic domain may result in negative consequences to students mental health, such as anguish and discomfort due to time passing while tasks remain incomplete, perceptions of incompetence, as well as unpleasant feelings such as anxiety and guilt (Kerbauy, 2001). These negative thoughts and emotions may impair students' learning and academic performance (Sampaio and Bariani, 2011). In relation to reasons why students are procrastinating, Solomon and Rothblum (1984) found that students appear to procrastinate on tasks that they do not like. Based on these results one may presume the students procrastinate when facing academic activities perceived as unpleasant. However, it is also possible that students procrastinate on things that we love. The purpose of this study was to assess whether students procrastinate on activities that they are passionate about.

The Coronavirus Disease 2019 (COVID-19) pandemic has made engaging in procrastination easier, even when a given activity is loved by students. As of February 2020, academic activities in Brazil started to be carried out in virtual environment as a way to meet the World Health Organization's (WHO) recommendations of physical distancing, demanding important adaptations from students, professors, and other professionals from the academic community. In this sense, research has shown that this long period of physical distancing, reductions in social communication, and changes to learning formats contribute to reduced engagement in studies among students, as well as increases in procrastination behaviors (Jia et al., 2020), and psychological distress levels (Maia and Dias, 2020). Therefore, the importance of studying these aspects at the time of the pandemic is also necessary.

\subsection{Academic procrastination}

Procrastination is defined in general as the voluntary delay of an intended action, despite negative consequences (Klingsieck, 2013; Sirois and Pychyl, 2013; Steel, 2007). Procrastination can be understood as the tendency to postpone activities required to achieve a given goal and is very common in the academic context wherein students may put off a task deliberately because they do not know how to accomplish it or have an aversion to it (Lay, 1986). More specifically, Rothblum et al. (1986) defined the concept of academic procrastination as a dysfunctional and 
irrational delay of academic tasks, usually associated with anxiety and negative consequences such as academic failure and ill-being (e.g., anxiety).

In addition, many other authors have reported that academic procrastination is related to maladaptive outcomes such as feelings of discomfort, stress, and guilt (e.g., Klingsieck, 2013). For instance, Rebetez et al. (2015) showed that students who procrastinate do not conduct behaviors in line with their values and may therefore delay an objective, even when it is important. Their findings further show that procrastination involves low extrinsic motivation and self-regulation, as well as difficulties related to unpleasant emotions. The studies of Chen et al. (2020) further provide evidence of the predictive role of procrastination in negative emotions. These authors identified emotional attitudes related to procrastination, by tracking $18,809,276$ posts by $5,613,807$ users on social networks (Facebook, Twitter, Sina Weibo, and Baidu Tieba). Based on a neurolinguistic processing algorithm, together with assessments focusing on the sentiments posted, they categorized these emotions and found that procrastination was perceived as a negative bahavior caused by self-regulation failure. In addition, Yildirim and Demir (2019) found procrastination to be a strong predictor of avoidant behaviors and self-handicapping among undergraduate students. In line with these findings, several other authors have found a positive association between procrastination in the academic domain and negative emotional experiences (Blunt and Pychyl, 1998; Fee and Tangney, 2000; Pychyl, Lee, Thibodeau and Blunt, 2000; Saddler and Buley, 1999). Thus, procrastination can be pinpointed as being the result of a failure in self-regulation or a mood repair strategy in which the priority is to feel good in the short term (i.e., by avoiding a task), while disregarding long-term objectives (e.g., performing well in a given class, Pychyl and Flett, 2012; Pychyl and Sirois, 2016; Sirois and Pychyl, 2013). This data demonstrates the detrimental effects of procrastination.

\subsection{The dualistic model of passion}

According to Vallerand (2015), passion can be defined as an individual's predisposition to perform activities that he/she values, appreciates and in which he/she invests time and energy. The construct is formed by two dimensions, harmonious passion (HP) and obsessive passion (OP). Each of these dimensions generate, in their own way, a strong commitment to a given activity, but differ in terms of how this passionate activity is internalized into one's identity. In the former (HP), the subject voluntarily engages in the activity, allowing him/her to align the passionate activity with other personal desires and to consciously internalize the experience into his/her identity. In the latter (OP), conversely, the individual is engaged in an inflexible and maladaptive way, experiencing negative feelings such as anxiety, as well as internalizing experiences in an uncontrolled fashion (Vallerand, 2015; Vallerand and Houlfort, 2019; Vallerand et al., 2003).

This two-dimensional understanding of the passion construct, also called the Dualistic Model of Passion (DMP, Vallerand et al., 2003), has been used in different contexts and has provided the basis for other studies. In the organizational context, studies have indicated that harmonious passion is positively related to the 
job satisfaction of physicians (Pereira, Ferreira and Valentini, 2019) and university teachers in physical education courses (Prates et al., 2019). One study, Pereira et al. (2018), found that harmonious passion generates more positive than negative feelings with regard to occupational activities. Jones (2020) observed a negative association between harmonious passion and procastination in the work environment in American and Chinese samples, while obessive passion was positively associated with procrastinatory behaviors only among Chinese respondents. The author also suggested the protective role of the harmonious passion on procrastination and other outcomes from work environments.

In addition, Brazilian workers with harmonious passion showed more commitment to their jobs, while those with obsessive passion showed lower levels of commitment and positive affect. Conclusions presented by Salessi and Omar (2018) with Argentinian professionals, are in alignment with Brazilian studies, showing that passion for work, in its two variants, to be positively associated with satisfaction and the state of flow; however these ties are superior when individuals possess harmonious passion for their jobs. In the context of sports, Peixoto, Nakano, Castillo, Oliveira and Balbinotti (2019) also observed that both harmonious and obsessive passion were positively related to the number of hours per week that Brazilian athletes dedicated to physical activity.

On the other hand, the studies of Lalande et al. (2017), involving a North American sample, indicated that low levels of satisfaction in a particular important area of life may contribute to a subject having an overdependent, obsessive passion for some other activity for which he/she already has a passion, such as playing an instrument, practicing a sport, or reading. Accordingly, their conclusion was that obsessive passion seems to play a compensatory role in the lives of subjects that do not exhibit satisfaction beyond the passionate activity. The studies of Bélanger et al. (2019), with North American students, complement these findings, confirming that people with obsessive passion engage in activities with just one end goal in mind, neglecting other goals in life, while people with harmonious passion seek to accomplish more than one objective at the same time.

Taking into consideration the educational context, the concept of passion has gained international prominence, as this phenomenon permits an understanding of the way students relate to their studies and the inherent adaptive and maladaptive consequences thereof (Stoeber et al., in press; Abdelati and Salama-Younes, 2016). However, very few studies applying the DMP to the educational context in Brazil are available. Although ample evidence exists demonstrating both the positive and negative outcomes of passion across a variety of settings, no study so far has focused on the role of passion for an activity on procrastination within the purview of this activity and how it may may be related to positive and negatives outcomes in a student's life and health. This represents the overaching goal of this study. 


\subsection{The present study}

The present study had two objectives. The first objective was to examine the associations between students' harmonious and obsessive passion for studying and the following variables: academic procrastination, satisfaction with life, and psychological distress. It was expected that harmonious passion would have a significant negative relationship with procrastination, while obsessive passion would have a significant positive relationship with procrastination. Further, procrastination would negatively associated with life satisfaction, and be positively associated with psychological distress.

The second objective was to assess the effects of each subtype of passion on measures of procrastination, as well as the effects of procrastination on the life satisfaction and psychological distress. As seen in Fig. 1, it was hypothesized that harmonious passion would be negatively linked to academic procrastination, while obsessive passion would be positively linked to academic procrastination. Additionally, there is substantial evidence in the current literature as to the link between academic procrastination and negative variables (e.g. anxiety, stress) to substantiate a hypothesis that academic procrastination is negatively related to satisfaction with life and positively related to psychological distress. Similarly, substantial evidence support the hypothesis thet harmonious passion would be positively associated to satisfaction with life and negatively associated to psychological distress. On the other hand, obsessive passion is hypothesized to lead to lower levels on satisfaction with life and higher levels of psychological distress.

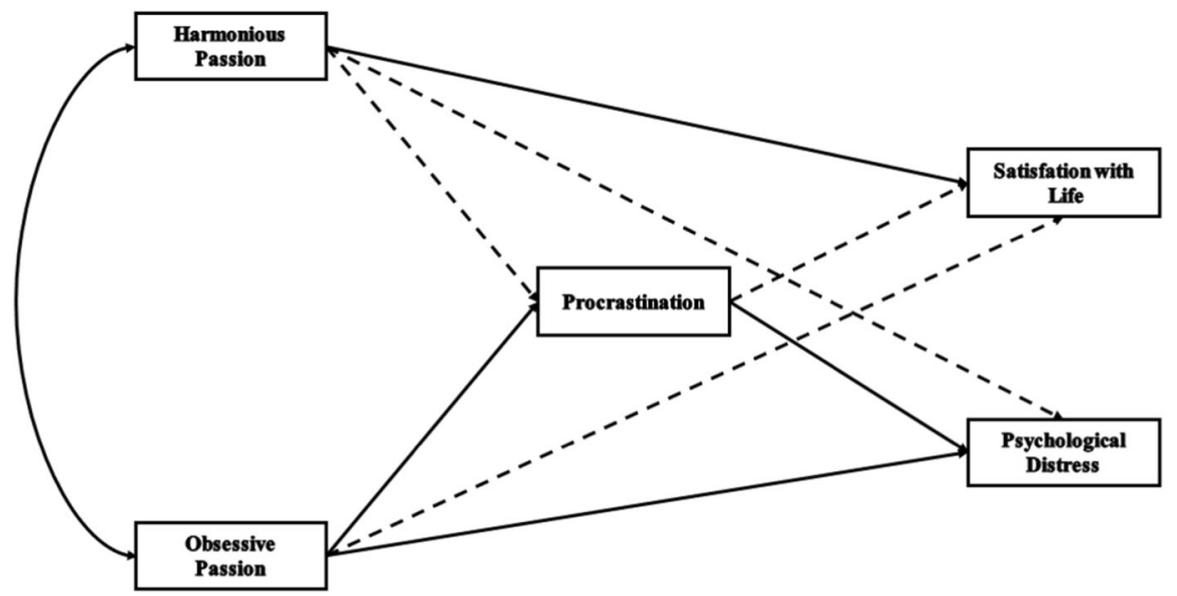

Fig. 1 Hypotethical model of the relationship between dimension of passion, procrastination, satisfaction with life and psychological distress among students. Note: Continuous line represents positive association, dashed line represents negative association between variables. Procratination here refered a Academic procrastination specifically 


\section{Method}

\subsection{Participants}

The sample was comprised of 416 (72.4\% undergraduate and $27.6 \%$ graduate) students, from public and private institutions, who were mostly female $(78.1 \%)$ and single $(82.2 \%)$. Considering that the participants were all students, $65 \%$ of the sample had no employment and only studied. There were students from different areas of knowledge. The most frequent courses were: Psychology (22\%), Physical Education (14\%), Medicine (11\%), and Law (6\%). All students were taking classes online due to adjustments employed by universities to meet social isolation suggestions by WHO. This was due to data collection taking place while the world was dealing with the Coronavirus Pandemic (COVID-19).

\subsection{Instruments}

\subsubsection{Passion}

Passion was measured using the Passion Scale-PS (Marsh et al., 2013; Vallerand et al., 2003). The Passion Scale consists of two dimensions of passion: harmonious passion (6 items, e.g., "My studies are in harmony with the other activities in my life") and obsessive passion (6 items, e.g., "I have difficulties controlling my urge to do my studies"). Responses were given via a seven-point Likert scale ranging from 1 "Not agree at all" to 7 "Very strongly agree". At least 20 studies have supported the factorial structure of the Passion Scale using either exploratory or confirmatory factor analysis (Vallerand, 2015). In addition, the Passion Scale has been validated in at least 12 languages (Vallerand and Rahimi, in press). Studies have adapted the instrument to Brazilian Portuguese and assessed the psychometric properties indicating suitability of the internal structure of the PS to the two-factor theoretical proposal, as well as demonstrated good levels of reliability for the respective factors $(\mathrm{HP}=0.81, \mathrm{OP}=0.75$; Peixoto et al., 2019).

In order to test the Passion Scale's internal structure, a Parallel Analysis (PA) and Exploratory Factor Analysis (EFA) using the Robust Diagonally-Weighted Least Squares (RDWLS) estimation method with Robust Promin rotation were performed (Lorenzo-Seva and Ferrando, 2019). The results suggested the retention of two factors correlated with each other $(r=0.59)$, with the content that remained in each group consistent with the original structure of the scale, arranged into harmonious passion and obsessive passion. The factor loadings for the harmonious passion items ranged from 0.43 to 0.94 , while the loadings for the obsessive passion items ranged from 0.48 to 0.94 . The structure accounted for $61.83 \%$ of explained variance and both factors presented good reliability indexes (HP, $\alpha=0.83$ and $\mathrm{OP}, \alpha=0.84$ ). 


\subsubsection{Academic procrastination}

Procrastination was measured using the Pure Procrastination Scale (PPS) devised by Steel (2010), consisting of 12 items which measure three dimensions of procrastination. Items for decisional delay $(\alpha=0.83)$, implemental delay $(\alpha=0.87)$ and delays in lateness/timeliness $(\alpha=0.85)$ are answered via a five-point Likert scale ranging from 1 "Very seldom or not true of me" to 5 "Very often true of me", in which higher scores indicated a higher level of procrastination. Rocha (2019) adapted this scale to Brazilian Portuguese using a sample of 1,456 university students, $76.7 \%$ of which were female and the average age was $26.06(S D=6.5)$. Exploratory and confirmatory factor analysis indicated the adequacy of 11 items in a second-order model, in which procrastination was explained by three specific factors: decisional delay (e.g., "I delay making decisions until it's too late"), implemental delay (e.g., "I am continually saying "I'll do it tomorrow"), and lateness/timeliness (e.g., "I don't get things done on time), as well as a superior general factor, in addition to good internal consistency as indicated by Cronbach's alpha $(\alpha=0.91)$. Given that the PPS was originally designed to examine general procrastination and our aim in the present study was to examine procrastination with focus on the academic context specifically, only the items referring to implemental delay and the lateness/timeliness subscales of the PPS score were used to compose a general academic procrastination score (8 items, $\alpha=0.88$ ).

\subsubsection{Satisfaction with life}

Satisfaction with life was measured using the Satisfaction with Life Scale (SWLS), which consists of 5 statements that assess perceived satisfaction regarding an individual's condition of life (e.g., "In most ways my life is close to my ideal") on a seven-point Likert scale rating from 1 "Strongly disagree" to 7 "Strongly agree" (Diener et al., 1985). Psychometric studies indicate the suitability of the instrument for a Brazilian population and good internal consistency as indicated by Cronbach's alpha $(\alpha=0.87$; Zanon et al., 2013).

\subsubsection{Psychological distress}

Psychological distress was measured using the Depression, Anxiety and Stress Scale (DASS-21), which consists of 21 items assessing and distinguishing symptoms of depression, anxiety, and stress based on the Tripartite Model (Lovibond and Lovibond, 1996). The scale is structured in three components, each grouping together seven items, namely: (a) specific factor of depression, assessing anhedonia, depressed mood, absence of positive emotions, (e.g., "I felt downhearted and blue"); (b) specific factor of anxiety, discriminating somatic tension and hyperactivity (e.g., "I was aware of the dryness of my mouth") and, (c) specific factor of stress, with a focus on difficulty relaxing, agitation, irritability; (e.g., "I found it hard to wind down,"), assessed on a four-point Likert scale ranging from 0 "Did not apply at all" 
to 3 "Applied a lot or most of the time". Psychometric studies indicate suitability of the instrument for the Brazilian context (Machado et al., 2013; Patias et al., 2016). Current proposals for assessment of the DASS-21 have shown adequacy of the instrument through a bifactor structure determined by three specific factors (stress, depression and anxiety) and one general factor (psychological distress; Peixoto et al., in press).

\subsubsection{Demographics}

A sociodemographic questionnaire was developed specifically for the present study assessing characteristics such as sex, age, schooling, graduation course, graduation period, marital status, federal state, place of residence, whether or not isolation measures were being observed, and if online classes were being taken.

\subsection{Procedure}

With the approval of the ethics committee, the data were inserted into Google Forms with the link subsequently being made available on the researchers' social media pages. To gain access to the study's instruments, participants had to agree with the Free and Informed Consent form presented on the first page, attesting to voluntary participation. The instruments were applied in the following order: sociodemographic questionnaire, the Passion Scale (PS), the Pure Procrastination Scale (PPS), the Depression, anxiety and stress scale (DASS-21), and the Life Satisfaction Scale (LSS). The average time to complete the form was approximately $20 \mathrm{~min}$.

\subsection{Data analysis}

The relationships between the constructs were examined and analyzed using Pearson's correlation. The assessments of the theoretical models were performed through Structural Equation Modeling (SEM), using Path Analysis which allows the testing of global models based on multiple regression analyses. The quality of the data fit to the theoretical model was established by means of the goodness-of-fit indices commonly used in the literature, such as the Comparative Fit Index (CFI), the Tucker Lewis Index (TLI), and the Root Mean Square Residual (RMR); and by the significance of the total, direct, and indirect effects observed. The significance level adopted was $P<0.05$ (Marôco, 2010) and the software package used was AMOS v 22.0 .

\section{Results}

Means, standard deviations, and correlations among the model variables appear in Table 1. As can be seen, the means reflect the presence of passion for one's studies as well as the presence of academic procrastination. In terms of the constructs, 
Table 1 Means, standard deviations, and pearson correlations among the model variables

\begin{tabular}{lllllll}
\hline Constructs & $\mathrm{M}(\mathrm{SD})$ & $\mathrm{HP}$ & OP & Proc & LS & Distress \\
\hline HP & $4.64(1.34)$ & 1 & & & & \\
OP & $3.14(1.31)$ & $0.44^{* *}$ & 1 & & & \\
Proc & $2.55(0.97)$ & $-0.38^{* *}$ & -0.02 & 1 & & \\
LS & $4.13(1.41)$ & $0.39^{* *}$ & 0.01 & $-0.37^{* *}$ & 1 & \\
Distress & $1.30(0.76)$ & $-0.25^{* *}$ & $-0.10^{*}$ & $0.34^{* *}$ & $-0.34^{* *}$ & 1 \\
\hline
\end{tabular}

$M$ mean, $S D$ standard deviation, $H P$ harmonious passion, $O P$ obsessive passion, $P r o c$. Academic procrastination, $L S$ life satisfaction, Distress Psychological distress; $* * P<0.01$. $* P<0.05$

the Passion Scale was correlated with the other instruments, namely the PPS, the SWLS, and the DASS-21. Correlation results showed that students' HP was negatively and moderately related $(r=-0.38, P<0.001)$ with academic procrastination. The OP factor, on the other hand, was not related with academic procrastination $(r=-0.02, P=0.628)$. Finally, academic procrastination had a moderate negative relationship with life satisfaction $(r=-0.37, P<0.001)$ and a positive one with psychological distress $(r=0.34, P<0.01)$.

In the path model, presented in Fig. 2, HP and OP were tested as predictors of life satisfaction and psychological distress, and academic procrastination was examined as a mediating variable. Results demonstrated excellent fit to the data: $(\chi 2$ $(\mathrm{df}=0)=0, n s, \mathrm{CFI}=1.00, \mathrm{TLI}=1.00, \mathrm{SRMR}=0.0)$. More specifically, HP negatively $(\beta=-0.45, P<0.001)$, and OP positively $(\beta=0.17, P<0.001)$, was linked to academic procrastination that, in turn, was negatively linked to life satisfaction

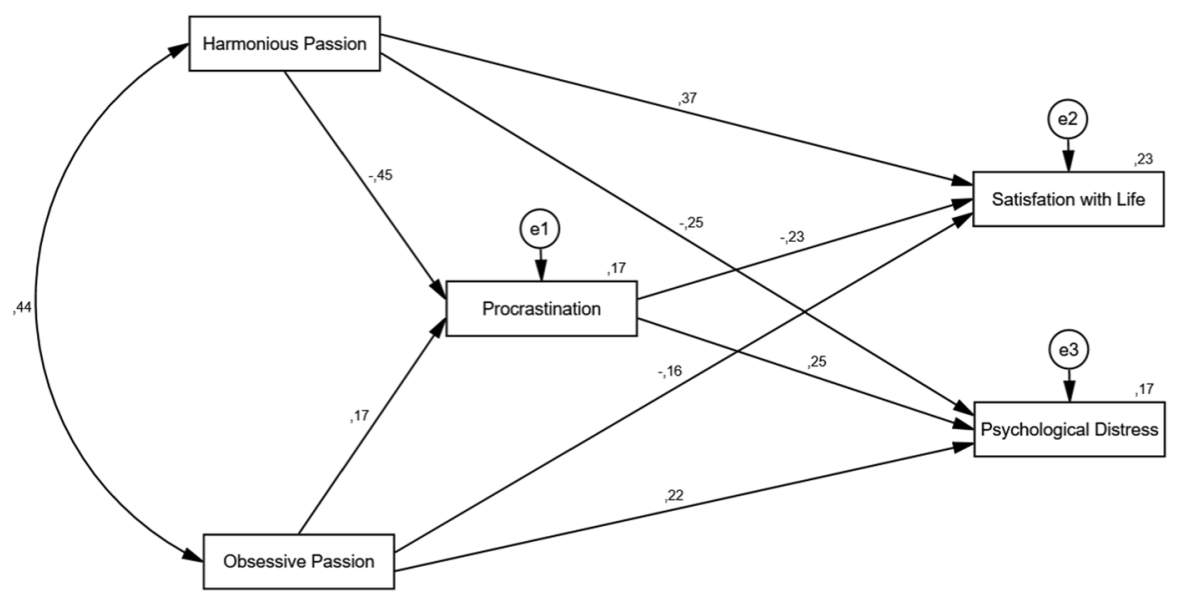

Fig. 2 Model of the relationships between the two types of passion on two outcome variables, satisfaction with life and psychological distress, mediated by procrastination Note. In addition to the trajectories shown in the models, an association was established between the estimated error for the outcome variables life satisfaction and psychological distress $(r=-0.19, P<0.01)$. All paths were statistically significant with $P$-value $<0.01$ 
$(\beta=-0.23, P<0.001)$ and positively linked to psychological distress $(\beta=-0.23$, $P<0.001)$. However, direct effects were also observed, such that HP was positivelly associated $(\beta=0.37 P<0.001)$, while OP was negatively associated life satisfaction $(\beta=-0.16, P<0.01)$. Additionally, HP negatively $(\beta=-0.25 P<0.001)$, while OP positively $(\beta=0.25, P<0.001)$, associated to psychological distress. Finally, the results showed that this model explained $17 \%$ of the variability in academic procrastination, $23 \%$ in life satisfaction, and $17 \%$ in psychological distress.

The mediational role of academic procrastination on the model was then tested (through Structural Equation Modeling (SEM) using Path Analysis), these results indicate a partial mediation of academic procrastination in the relationship among $\mathrm{HP}$ and satisfaction with life (indirect effect $=-0.10$ ), and psychological distress (indirect effect -0.11), as well as partial mediation of academic procrastination in the relationship among OP, satisfaction with life (indirect effect -0.04), and psychological distress (indirect effect 0.04). Additionally, when the academic procrastination was excluded from the model, the total effect of HP over satisfaction with life was $\beta=0.48(P<0.001)$, and over psychological distress was $\beta=-0.37(P<0.001)$. The total effect of OP over satisfaction with life was $\beta=-0.27(P<0.001)$, and over psychological distress was $\beta=-0.20(P<0.001)$, indicating that with the inclusion of academic procrastination on the model the effects of HP and OP on satisfaction with life and psychological distress were reduced.

\section{Discussion}

This study aimed to explore the associations between Brazilian students' passion for studying, academic procrastination, satisfaction with life, and psychological distress when students were doing online classes to adhere to the governmental rules of physical distancing due to the COVID-19 pandemic. This main objective was operationalized through two specific objectives: (1) to assess the correlations among the variables studied, and (2) to estimate the role of each passion dimension on academic procrastination and the consequence of this procrastination on satisfaction with life and psychological distress. Overall, the findings corroborate the hypotheses of association among variables and indicate that HP for studying was protective against academic procrastination and indicators of mental health (satisfaction with life and psychological distress). On the other hand, OP for studying promoted academic procrastination and hindered students' psychological well-being.

The results of the path model present a vital understanding of the relationships between the measured constructs. More specifically, one can highlight the positive effect of harmonious passion and the negative effect of obsessive passion on academic procrastination. Thus, it is possible to say that students with HP do not procrastinate but manage to find a balance with other areas of life (since they are more satisfied with life in general), while students with OP engage in procrastination because they are unable to manage all the areas in their lives, and finding a balance is quite difficult with this rigid type of passion.

These results corroborate the current literature, which indicates that people who have harmounious passion for their activities of interest can concentrate fully on the 
task and experience positive results, such as positive emotions during the activity, as well as the perception of satisfaction and well being. Additionally, when prevented from engaging in the activity they are passionate about, they are able to focus their energy and attention on other tasks that need to be done. Therefore, these people are in control of the activity and show efficiency for deciding when to participate or not (Vallerand, 2012; Vallerand and Houlfort, 2019), which prevents students from engaging in procrastinatory behaviors. In contrast, people with obsessive passion are uncompromising when engaging in the activity, showing an uncontrollable desire to perform the task considered important. Although this persistence in performing the activity may lead to benefits, such as better performance over time, it can cause people to put pressure on themselves, to experience negative emotions during the activity (Vallerand, 2015; Vallerand and Houlfort, 2019), to be frustrated and have ruminative thoughts when prevented to perform the activities of interest (Vallerand, 2012). Thus, students with high levels of obsessive passion tend to be overly concerned with the activities they are passionate about, even when they have other important activities to do. This creates conflict with the other domains of life, as well as feelings of guilt and anxiety, resulting in a tendency to engage in procrastinatory behaviors (Doty et al, 2020).

This challenge in controlling or being controlled by the activity of interest, associated with the experience of positive or negative emotions arising from different types of passion for students' studies may be especially difficult given the physical isolation period caused by the pandemic, which has forced students to refrain from activities previously carried out in a variety of environments, such as physical exercise at the gym and studies in the library, which are all now restricted to the domestic environment. These new studying conditions radically changed students' learning experience, transformed it to a virtual environment, and placed pressure on students to have more organizational capacity to manage the different tasks and distractions present in their homes (Jia et al., 2020; Strielkowski, 2020). Results from the present study demonstated that having an HP for one's studies functioned as a protective factor against academic procrastinaton, whereas having an OP created a risk factor towards academic procrastination. Moreover, these results can extend beyond the scope of the current pandemic, considering that there is evidence of procrastination behaviors among students involved in online study programs (Rakes and Dunn, 2010; Michinov et al., 2011), as well as the growing investment of Brazilian universities to expand this type of education model (Bezerra et al., 2020).

The model also showed evidence that academic procrastination has negative effects on life satisfaction, which is consistent with the study of Soares, AndradeFilho, Ribeiro and Rezende (2020) with a Brazilian graduate sample, in which procrastination was negatively related with variables such as subjective well-being, positive emotions, and satisfaction with life after graduation. In the same direction Beutel et al. (2016), observed on a representative German community sample that procrastination was negatively associated with satisfaction across different life domains. Also, Balkis (2013) showed that academic procrastination negatively predicted academic life satisfaction. This set of research results indicates the when students engage in procrastination, they feel their lives are uncontrollable and the 
academic experience becomes unpleasant for them, and this may affect students' life satisfaction.

Relatedly, the present findings demonstrate that students who procrastinate also experience psychological distress. These findings are in line with previous research (e.g., Balkis and Duru, 2016; Fee and Tangney, 2000; Pychyl et al., 2000). More specifically, Beutel et al. (2016), found a positive association between procrastination and perceived stress, depression, anxiety, fatigue, and loneliness. In the same way, Solomon and Rothblum (1984) observed that procrastination was associated with depression, anxiety, irrational cognitions, and low self-esteem, which led the authors to conclude that procrastination is close related to general negative effect and cognitions about oneself. Thus, scholars emphazise that negative emotions are essential to the experience of procrastinaton and therefore, the present findings support such research.

Additionally, the direct effects of the type of passion on the outcome variable "life satisfaction" remain positive with HP and negative with OP, while the direct effects on "psychological distress" were negative with HP and positive with OP. This finding enables us to state that, besides what has already been highlighted regarding students with HP having a higher level of satisfaction with life, they also have lower levels of distress, whereas with OP, the effects are completely the opposite. Thus, our findings support results obtained by Vallerand (2015) and Curran, Appleton, Vallerand and Standage (2015), in which people with more HP experience more positive emotions and people with more OP experience more negative emotions.

The study results corroborate previous research showing that HP also contributes to wellbeing indicators, such as positive affect, flourishing, self-esteem, flow, self-efficacy, meaning in life, and life satisfaction, while HP is negatively related to depression, anxiety, and burnout (Abdelati and Salama-Younes, 2016; Curran et al., 2015; Peixoto, Santos, Romano and Palma, in press; Vallerand, Chichekian and Paquette, 2020). This allows us to make the inference that HP for studies leads to some positive educational experiences, which promote psychological well-being, even after engaging in the task (Vallerand, 2015). On the other hand, although OP can contribute to academic success, it can indicate higher levels of psychological distress, such as depression, anxiety, and negative affect, and it is negatively associated with satisfaction with life. Thus, establishing a positive relationship with one's studies (HP) is a way to have positive experiences and more adaptive results, and therefore, being closer to a life that is worth living (Chichekian and Vallerand, 2018).

Finally, this research brings a secondary, but also relevant contribution, corresponding to the adaptation and estimation of validity evidence and reliability of the PS in the Brazilian educational context, the exploratory factor analysis suggested the same two-factor configuration as the original scale proposed by Vallerand et al. (2003). Furthermore, coefficients for internal consistency were good for both passion scale scores. These results add validity and reliability evidence regarding the assessment of the construct as the basic theory proposes. Additionally, these results are consistent with the literature, that has demonstrated good psychometric properties of adapted versions of the PS for thirteen different cultures (see Vallerand and Rahimi, in press). 


\subsection{Limitations and future research}

The present study has some limitations, one of which is the fact that this study employed a cross-sectional design to assess the correlations between passion, academic procrastination, life satisfaction, and psychological distress, which prevents the inference of causality between variables. In addition, data was gathered using self-report measures, which increases the risk of response bias. To address these limitations, it is suggested to use response bias control methods in future research. In addition, longitudinal designs can increase the understanding of how these variables interact over time. Lastly, the vast majority of participants were female, and therefore, it is important to assess whether this model is valid for a more balanced sample, allowing comparisons between groups, in order to understand whether the way one relates to studying can change in relation to gender.

The characteristics of academic procrastination in relation to passion for studying may be explored in more depth, as some researchers, such as Chu and Choi (2005), have proposed that not all expressions of procrastination are harmful or have negative effects; however, the scale used in the present study does not propose this differentiation. Future studies may also seek to add evidence of validity to the structure of the PS in its adapted version, testing confirmatory models, invariance regarding the sample's characteristics and comparing samples with those of other cultures.

In addition, it would be relevant to investigate possible differences on the effects of passion and procrastination on mental health, considering the knowledge areas, courses, levels (undergraduate and graduate), and sex. It is not yet known if passion (mainly Harmonious Passion) for the activity can attenuate the effects of procrastination and increase levels of mental health depending on these aspects. However, some studies have shown differences in the levels and effects of procrastination between different groups. For example, Artino-Junior and Stephens (2009) showed that graduate students had higher levels of critical thinking and lower levels of procrastination when compared to undergraduate students. Similar results were found by Özer (2011), who investigated the difference among sex and levels (high school, undergraduate, and graduate students) on procrastination frequency and prevalence. The results showed that there was no difference between sexes, however, undergraduate students showed higher levels of procrastination than the graduate students, and both were showed higher levels of procrastination than the high school group.

\section{Conclusion}

Results from the current study provide further evidence as to the relationships between the dualistic model of passion, academic procrastination, and mental health indicators, as well as the mediating role of academic procrastination in such processes. The findings suggest that students with higher levels of HP for their studies tend to not engage in procrastination, to report greater levels of satisfaction with life and lower levels of psychological distress. On the other hand, higher levels of OP lead to engagement in procrastination, promoting decreases in satisfaction with life 
and increases in psychological distress. In conclusion, the results corroborate the initial hypothesis that students can engage in procrastination behaviors and hinder their subjective well-being, even in activities they are passionate about, depending on the type of passion directed towards the activity.

Authors' contributions All authors made substantial contributions to the conception, analysis and interpretation of data of the work; drafted the work or revised it critically for important intellectual content; approved the version to be published; and agree to be accountable for all aspects of the work in ensuring that questions related to the accuracy or integrity of any part of the work are appropriately investigated and resolved. Specificaly, material preparation, data collection and analysis were performed by Evandro Morais Peixoto. The first draft of the manuscript was written by Ana Celi Pallini, Evandro Morais Peixoto e Marcus Vinícus Silva and all authors commented on later versions of the manuscript. Robert J. Vallerand and Sonia Rahimi revised it critically for important intellectual content. All authors read and approved the final manuscript.

Funding The authors did not receive support from any organization for the submitted work.

Data Availability Not applicable.

Code availability Not applicable.

\section{Declaration}

Conflict of interest All author declare that they had no conflict of interest in conducting this research.

Ethics approval This study was conducted with the approval of the ethics committee.

Consent to participate All participants agreed with the Free and Informed Consent form presented on the first page, attesting to voluntary participation.

Consent for publication All participants had information and agree about future publication. We garanted the anonymous of they identidad.

\section{References}

Abdelati, S. B., \& Salama-Younes, M. (2016). Passion types and subjective well-being for Saudi women: Exploratory study. Indian Journal of Positive Psychology, 7(3), 325-334

Balkis, M. (2013). Academic procrastination, academic life satisfaction and academic achievement: The mediation role of rational beliefs about studying. Journal of Cognitive and Behavioral Psychotherapies, 13(1), 57-74

Balkis, M., \& Duru, E. (2016). Procrastination, self-regulation failure, academic life satisfaction, and affective well-being: Underregulation or misregulation form. European Journal of Psychology of Education, 31, 1-21. https://doi.org/10.1007/s10212-015-0266-5

Beutel, M. E., Klein, E. M., Aufenanger, S., Brähler, E., Dreier, M., Müller, K. W., \& Wölfling, K. (2016). Procrastination, distress and life satisfaction across the age range-a German representative community study. PLoS ONE, 11(2), e0148054. https://doi.org/10.1371/journal.pone.0148054

Bélanger, J. J., Schumpe, B. M., \& Nisa, C. F. (2019). How passionate individuals regulate their activity with other life domains: A goal-systemic perspective. Journal of Personality, 87(6), 1136-1150. https://doi.org/10.1111/jopy.12463 
Bezerra, K. P., Costa, K. F. L., Oliveira, L. C., Fernandes, A. C. L., Carvalho, F. P. B., \& Nelson, I. C. A. S. R. (2020). Remote teaching in state public universities: The future that is present. Research, Society and Development, 9(9), 359997226. https://doi.org/10.33448/rsd-v9i9.7226

Blunt, A., \& Pychyl, T. A. (1998). Volitional action and inaction in the lives of undergraduate students: State orientation, procrastination and proneness to boredom. Personality and Individual Differences, 24(6), 837-846. https://doi.org/10.1016/S0191-8869(98)00018-X

Chen, Z., Zhang, R., Xu, T., Yang, Y., Wang, J., \& Feng, T. (2020). Emotional attitudes towards procrastination in people: A large-scale sentiment-focused crawling analysis. Computers in Human Behavior, 110, 106391. https://doi.org/10.1016/j.chb.2020.106391

Chu, A. H. C., \& Choi, J. N. (2005). Rethinking procrastination: Positive effects of" active" procrastination behavior on attitudes and performance. The Journal of social psychology, 145(3), 245-264. https://doi.org/10.3200/SOCP.145.3.245-264

Diener, E., Emmons, R. A., Larsen, R. J., \& Griffin, S. (1985). The satisfaction with life scale. Journal of Personality Assessment, 49(1), 71-75. https://doi.org/10.1207/s15327752jpa4901_13

Ellis, A. \& Knaus, W. J. (1977). Overcoming procrastination. Sgnet Books.

Fee, R. L., \& Tangney, J. P. (2000). Procrastination: A means of avoiding shame or guilt? Journal of Social Behavior and Personality, 15(5), 167-184

Goroshit, M., \& Hen, M. (2019). Academic procrastination and academic performance: Do learning disabilities matter? Current Psychology. https://doi.org/10.1007/s12144-019-00183-3

Harriott, J., \& Ferrari, J. R. (1996). Prevalence of procrastination among samples of adults. Psychological Reports, 78, 611-616. https://doi.org/10.2466/pr0.1996.78.2.611

Jia, J., Jiang, Q., \& Lin, X. H. (2020). Academic anxiety and self-handicapping among medical students during the COVID-19 pandemic: A moderated mediation model. (Research square), 1-22. https:// doi.org/10.21203/rs.3.rs-77015/v1

Jones, R. P. (2020). Passion meets procrastination: comparative study of negative sales associate behaviours. International Journal of Retail and Distribution Management, 48(10), 1077-1098. https://doi. org/10.1108/IJRDM-06-2019-0200

Kerbauy, R. R. (2001). Procrastinação: Adiamento de tarefas [Procrastination: postponement of tasks]. In: R. A. Banaco (Org.). Sobre comportamento e cognição: aspectos teóricos, metodológicos e de formação em análise do comportamento e terapia cognitiva [On behavior and cognition: theoretical, methodological and training aspects in behavior analysis and cognitive therapy] (pp. 445-452). São Paulo: ARBytes.

Klingsieck, K. B. (2013). Procrastination: When good things don't come to those who wait. European Psychologist, 18(1), 24-34. https://doi.org/10.1027/1016-9040/a000138

Lalande, D., Vallerand, R. J., Lafrenière, M. A. K., Verner-Filion, J., Laurent, F. A., Forest, J., \& Paquet, Y. (2017). Obsessive Passion: A Compensatory Response to Unsatisfied Needs. Journal of Personality, 85(2), 163-178. https://doi.org/10.1111/jopy.12229

Lay, C. H. (1986). At last my research article on procrastination. Joumal of Research in Personality, 20, 474-495. https://doi.org/10.1016/0092-6566(86)90127-3

Lorenzo-Seva, U., \& Ferrando, P. J. (2019). Robust Promin: a method for diagonally weighted factor rotation. LIBERABIT Revista Peruana de Psicología, 25, 99-106. https://doi.org/10.24265/liberabit. 2019.v25n 1.08

Lovibond, S. H., \& Lovibond, P. F. (1996). Manual for the depression anxiety stress scales. Psychology Foundation of Australia.

Maia, B. R., \& Dias, P. C. (2020). Ansiedade, depressão e estresse em estudantes universitários: o impacto da COVID-19 [Anxiety, depression and stress in university students: The impact of COVID-19]. Estudos de Psicologia, 37, e200067. https://doi.org/10.1590/1982-0275202037e200067.

Marôco, J. (2010). Análise de equações estruturais: Fundamentos teóricos, software \& aplicações. ReportNumber, Lda.

Marsh, H. W., Vallerand, R. J., Lafrenière, M.-A. K., Parker, P., Morin, A. J. S., Carbonneau, N., et al. (2013). Passion: Does one scale fit all? Construct validity of two-factor passion scale and psychometric invariance over different activities and languages. Psychological Assessment, 25(3), 796809. https://doi.org/10.1037/a0032573.

Michinov, N., Brunot, S., Le Bohec, O., Juhel, J., \& Delaval, M. (2011). Procrastination, participation, and performance in online learning environments. Computers \& Education, 56(1), 243-252. https:// doi.org/10.1016/j.compedu.2010.07.025

Özer, B. U. (2011). A cross sectional study on procrastination: who procrastinate more. International Conference on Education Research and Innovation, 18, 34-37 
Peixoto, E., Santos, S., Romano, A., \& Palma, P. (2021). Traços de Personalidade, Paixão e Autoeficácia: um estudo correlacional com universitários brasileiros [Personality traits, Passion and Self-efficacy: a correlational study with Brazilian university students]. Psicologia Saúde and Doença 22(1), 128141. https://doi.org/10.15309/21psd220112.

Prates, M. E. F., Both, J., \& Rinaldi, I. P. B. (2019). The physical education teachers and the passion for teaching activity in higher education. Journal of Physical Education. https://doi.org/10.4025/jphys educ.v30i1.3015

Pereira, M. M., Ferreira, M. C., \& Valentini, F. (2018). Evidências de validade da Escala de Paixão pelo Trabalho em Amostras Brasileiras [Validity Evidences of Passion towards Work Scale in Brazilian Samples]. PsicoUSF, 23(3), 151-162. https://doi.org/10.1590/1413-82712018230113

Pereira, M. M., Ferreira, M. C., \& Valentini, F. (2019). Occupational satisfaction of physicians: The impact of demands and resources. Paideia, 29(1), 1999. https://doi.org/10.1590/1982-4327e2920

Peixoto, E. M., Nakano, T. D. C., Castillo, R. A., Oliveira, L. P., \& Balbinotti, M. A. A. (2019). Passion scale: Psychometric properties and factorial invariance via exploratory structural equation modeling (ESEM). Paideia, 29, 1-10. https://doi.org/10.1590/1982-4327e2911

Peixoto, E. M., Oliveira, K. S., Campos, C. R. Gagnon, J. Zanini, D. S., Nakano, T. C., \& Bueno, J. M. H. (in press). DASS-21: Proposal of Psychological Distress Assessment by the bifactor Model and items analysis. Psico-USF.

Pychyl, T. A., \& Flett, G. L. (2012). Procrastination and self-regulatory failure: An introduction to the special issue. Journal of Rational- Emotive and Cognitive-Behvavior Therapy, 30(4), 203-212. https://doi.org/10.1007/s10942-012-0149-5

Pychyl, T. A., \& Sirois, F. M. (2016). Procrastination, emotion regulation, and well-being. In Procrastination, health, and well-being (pp. 163-188). London: Academic Press. https://doi.org/https://doi. org/10.1016/B978-0-12-802862-9.00008-6

Pychyl, T. A., Lee, J. M., Thibodeau, R., \& Blunt, A. (2000). Five days of emotion: An experience sampling study of undergraduate student procrastination. Journal of Social Behavior and Personality, 15(5), 239-245

Rakes, G. C., \& Dunn, K. E. (2010). The impact of online graduate students' motivation and self-regulationon academic procrastination. Journal of Interactive Online Learning, 9(1). http://www.ncolr. org/jiol/issues/pdf/9.1.5.pdf

Rebetez, M. M. L., Rochat, L., \& Linden, M. V. D. (2015). Cognitive, emotional, and motivational factors related to procrastination: A cluster analytic approach. Personality and Individual Differences., 76, 1-6. https://doi.org/10.1016/j.paid.2014.11.044

Rocha, R. Z. (2019). Pure procrastination scale e irrational procrastination scale: adaptação e evidências de validade para o contexto brasileiro [Pure procrastination scale and irrational procrastination scale: adaptation and validity evidence for the Brazilian contexto]. Dissertação de mestrado [Masters dissertation], Universidade Federal do Rio Grande do Sul. HY

Rothblum, E. D., Solomon, L. J., \& Murakami, J. (1986). Affective, cognitive, and behavioral differences between high and low procrastinators. Journal of Counseling Psychology, 33(4), 387-394. https:// doi.org/10.1037/0022-0167.33.4.387

Saddler, C. D., \& Buley, J. (1999). Predictors of academic procrastination in college students. Psychological Reports, 84(2), 686-688. https://doi.org/10.2466/pr0.1999.84.2.686

Salessi, S., \& Omar, A. (2018). Pasión por el Trabajo: Evidencias de Validez Discriminante, Predictiva e Incremental [Work Passion: Evidence of Discriminant, Predictive and Incremental Validity]. Psicologia Ciência e Profissão, 38(3), 522-536. https://doi.org/10.1590/1982-37030004752017

Sampaio, R. K. N., \& Bariani, I. C. D. (2011). Procrastinação acadêmica: um estudo exploratório [Academic procrastination: An exploratory study]. Estudos Interdisciplinares em Psicologia, 2(2), 242262. https://doi.org/10.5433/2236-6407.2011v2n2p242

Sirois, F. M., \& Pychyl, T. A. (2013). Procrastination and the priority of short- term mood regulation: Consequences for future self. Social and Personality Psychology Compass, 7(2), 115-127. https:// doi.org/10.1111/spc3.12011

Soares, A. K. S., de Andrade-Filho, J. A. L., Ribeiro, M. G. C., \& Rezende, A. T. (2020). Avaliando o papel da procrastinação acadêmica e bem-estar subjetivo na predição da satisfação com o programa de pós-graduação [Assessing the role of academic procrastination and subjective well-being in predicting satisfaction with the postgraduate program]. Ciencias Psicológicas, 14(1), 1-15. https://doi. org/10.22235/cp.v14i1.2078

Solomon, L. J., \& Rothblum, E. D. (1984). Academic procrastination: Frequency and cognitive-behavioral correlates. Journal of Counseling Psychology, 31, 503-509. https://doi.org/10.1037/0022-0167.31.4.503 
Steel, P. (2007). The nature of procrastination: A meta-analytic and the- oretical review of quintessential self-regulatory failure. Psychological Bulletin, 133(1), 65-94. https://doi.org/10.1037/0033-2909. 133.1.65

Strielkowski, W. (2020). COVID-19 pandemic and the digital revolution in academia and higher education. Preprints. https://doi.org/10.20944/preprints202004.0290.v1

Vallerand, R. J. (2012). The role of passion in sustainable psychological well-being. Psych Well-Being, 2(1), 161. https://doi.org/10.1186/2211-1522-2-1

Vallerand, R. J. (2015). The Psychology of passion: A dualistic model. Oxford University Press.

Vallerand, R. J., \& Houlfort, N. (2019). Passion for work: Theory, research, and applications.

Vallerand, R. J., \& Rahimi, S. (in press). On the psychometric properties of the Passion Scale. In A. Efklides, I. Alonso-Arbiol, T. Ortner, W. Ruch, \& F. J. R. van de Vijver (Eds.), Psychological Assessment in Positive Psychology. Hogrefe

Vallerand, R. J., Blanchard, C. M., Mageau, G. A., Koestner, R., Ratelle, C. F., \& Léonard, M. (2003). Les passions de l'âme: On obsessive and harmonious passion. Journal of Personality and Social Psychology, 85, 756-767. https://doi.org/10.1037/0022-3514.85.4.756

Vallerand, R. J., Chichekian, T., \& Paquette, V. (2020). Passion in Education: Theory, Research, and Applications. In: G. Liem \& D. McInerney (Eds.), Educational Interventions: A Sociocultural Perspective. Information Age Publishing.

Yildim, F. B., \& Demir, A. (2019). Self-handicapping among university students: The role of procrastination, test anxiety, self-esteem, and self-compassion. Psychological Reports. https://doi.org/10.1177/ 0033294118825099

Zanon, C., Bardagi, M. P., Layous, K., \& Hutz, C. S. (2013). Validation of the satisfaction with life scale to Brazilians: Evidences of measurement noninvariance across Brazil and US. Social Indicators Research, 119(1), 443-453. https://doi.org/10.1007/s11205-013-0478-5

Publisher's Note Springer Nature remains neutral with regard to jurisdictional claims in published maps and institutional affiliations.

Evandro Morais Peixoto is an Assistant Professor of Psychology in the Graduate Program in Psychology at Universidade São Francisco-Brazil. He holds a Grant on Productivity of the National Council of Scientific Researches CNPq-Level 2. He obtained his doctorate from the Pontifícicia Universidade Católica de Campinas and pursued his postdoctoral studies at the Universidade São Francisco.

Ana Celi Pallini is a doctoral student and holds a master's degree in the Graduate Program in Psychology at the Universidade São Francisco. She is a member of the Mental Health Psychological Assessment Laboratory (LAPSaM-III). Her research focuses on mental health and psychometrics, working on topics such as suicide, reasons for living, depression, positive psychology.

Professor Robert J. Vallerand is Full Professor of Social Psychology and the Director of the Research Laboratory on Social Behavior at the Université du Québec à Montréal. He holds a Canada Research Chair in Motivational Processes and Optimal Functioning which deals with his main research interests. He obtained his doctorate from the Université de Montréal and pursued postdoctoral studies at the University of Waterloo.

Dr. Sonia Rahimi holds a Ph.D. and M.A. in Educational Psychology from McGill University. She is currently working as a postdoctoral fellow with Dr. Robert Vallerand at the Université du Québec à Montréal in the Department of Psychology. Her research focuses on the emotional and motivational processes which underscore learning and personal development, with a specific focus on the role of procrastination.

Marcus Vinícus Silva is a Psychologist graduated from Centro Universitário de Itajubá - FEPI and master's student in the Graduate Program in Psychology at the Universidade São Francisco - USF. His research focuses on psychometrics, mental health and positive psychology. He is a member of the Center for Studies and Research in Sport and Exercise Psychology NuEPPEE. 